\title{
The Reality about the Curriculum Control and its Management in the South African Context
}

\author{
Dr Rakoma MM
}

\section{Dr Matshe PFA}

University of South Africa

\section{Doi:10.5901/mjss.2014.v5n16p435}

\section{Abstract}

\begin{abstract}
Curriculum used to be protected and be given the respect it deserves. It was regarded as a special place to be visited only by the professionals and the elite. However, things have changed with changing times, the very "secret garden" has been invaded by diverse pressure groups including politicians, the private sector and lay men. This paper analyses and presents the findings of a qualitative study that was conducted in the North-West Province (South Africa) to seek experiences and perceptions from purposively selected educational professionals, politicians, the religious group and the private sector representatives regarding their views concerning the "debate' over the curriculum control and its management. Questionnaires, interviews, observation, reflective journals and official documents were used to collect data.Qualitative data was analyzed using critical discourse analysis strategy. The findings revealed that each and every stakeholder feels ownership of the curriculum, politicians feel strongly that their involvement in curriculum control would ensure the relevance of the curriculum and that the needs of the clients are met. They further argue that the declining economy needs a purpose-focused curriculum. Thus, they have to account for tax payers ' monies used to fund educational projects. On the other hand; the professionals argue that they have rights to exercise control over the curriculum because of their teaching experience and specialized knowledge. The private sector believes that the education sector must produce people who must ultimately work in the private sector. They further argue that the private sector even financed some projects in higher education. Therefore, they insist to have a say over the curriculum control. The study recommended a collaborative model that would accommodate all legitimate stakeholders to participate in curriculum design, implementation, evaluation and management.
\end{abstract}

Keywords: contest; curriculum; control, stakeholders, management, transformation.

\section{Introduction}

According to du Plessis and Conley (2007:42), South Africa embarked on a radical transformation of education and training between 1989 and 1994. Before we focus on the current roles of different stakeholders in curriculum control, we will describe the evolution of curriculum development and the impact on different role players. One of the most challenging aspects of this transformation has been the adoption of an Outcomes-Based Education (OBE) approach that underpins the introduction of the new curriculum 2005 (C2005). OBE views itself as a drastic break from current educational practices and a means of providing educational success for all students. Steps in designing a learning programme include the understanding and interpreting of existing learning programmes, the study of prescribed policies by the Department of Education and the selection and preparation of suitable textual and visual resources for learning (du Plessis \& Conley, 2007:37). Teacher unions play a powerful role in South African Society. SADTU is the powerful and closest to government. It defines itself in opposition to the existing racially-based professional associations as being concerned with issues wider than the narrow workplace and salary concerns of these associations.

According to Chisholm (2003:7), many SADTU members were catapulted into leadership position in the new national and provincial departments after 1994. COSATU in turn, propelled the union into taking a greater interest in workplace issues. Both NAPTOSA and SAOU, once hostile to unions, have thawed in their attitudes to unionism and there is considerable cooperation between the unions. All three unions' federations played a role in the formulation and implementation of Curriculum 2005 from 1997 (Chisholm, 2003:7). SADTU played a critical role in keeping the fundamentals of outcomes-based education on the agenda, NAPTOSA and SADTU were insistent on a workable curriculum in the classroom and NAPTOSA in particular played a substantial role in the working committees and galvanizing members comment to revise the draft. On the other hand, teacher unions, universities, non-governmental organizations, governments departments and other members of the public submitted comments which supported the 
overall direction of the revision, but made specific recommendations for improvements. On the other hand a Christian political party argued that the new policy violated their human rights and constitutional rights to freedom of religion (Chidester, 2002:94). A common demand was the right to "private conscience, private enterprise and family values".

According to Wiles (2009:12), leaders can focus solely on maintaining the existing program through schedules reviews, control activities and limited problem solving, or the leader can broaden the work by providing vision, organization and motivation so that others may participate in schools design. In 1995, South African government began the process of developing a new curricular for the school system. There were two imperatives for this, first the scale of change in the world, the growth and development of knowledge and technology and the demands of the $21^{\text {st }}$ Century required learners to be exposed to different and higher level skill and knowledge than those required by the existing South African curricular. Secondly, South Africa had changed, the curricula for schools, therefore, required vision to reflect new values and principles especially those of the Constitution of South Africa (Department of Education(DoE), 2008:2).

\subsection{Statement of the problem}

The problem to be addressed is how to identify the relevant stakeholder to control and manage curriculum effectively without taking side amongst all stakeholders. There are different opinions about the roles which are played by different stakeholders regarding curriculum control. For the purpose of this study, by "contest" we are referring to the" words of war" or" the hot debate" amongst different groups regarding curriculum design, implementation, evaluation and control which has always been proved to be the biggest problem of teaching and learning in different schools in South Africa. If left unaddressed, it will have negative impact on our education system in the $21^{\text {st }}$ century. A particularly South African manifestation of community participation is that of stakeholders' participation. This implies that in educational governance structures, legitimate stakeholders should be granted the right to participate (Huysteen, 2005:51). Czerniewicz, Murray and Probyn (2000:8) emphasized the fact that a curriculum change has been, in part, a response to the need for the economy to become globally competitive. It has been driven by the state's needs to transform the old "apartheid" curriculum into one appropriate for a newly democratic society defined to create one that will meet the government's stated goals of equity, redress, democracy, access and participation.

There has been a struggle to remove Bantu Education which for black South African had been a means of restricting the development of the learner by distorting school knowledge to ensure control over the intellect of the learners and teachers, and propagating state propaganda .Curriculum 2005 or OBE system has introduced new learning styles implying changes from passive, rote learning to creative learning and problem solving through active participation in the learning process. The introduction of OBE in South Africa was not only an attempt to change the education system but also for the purpose of transforming society.

The Revised National Curriculum Statement (RNCS) regards teachers as key contributors' to educational transformation in South Africa. Teachers as agents of change are supposed to assume various roles and these include being mediators of learning, interpreters and designers of learning programmes and materials.

Curriculum Assessment Policy Statement (CAPS) has been introduced to strengthen the National Curriculum Statement in order to improve the quality of teaching and learning in schools. The CAPS document was sent out for public comment in September 2010. The comments were collated and the documents revised in accordance with the recommendations. The final step in the process involves a teacher union check on the do ability of the curriculum. (Curriculum news, 2011:7). People who were responsible for writing CAPS were A Ministerial Project Committee consisting of eight members and were responsible for preparing and completing the process. The criterion which was used for selecting those people was xperience in teaching the subject; level of knowledge of the subject; ability to write critically; ability to meet time constrains, and access to communication infrastructure. Although many studies were conducted in curriculum design, implementation and management, very little research has been done, if any, on the "cold war" over the curriculum control in the $21^{\text {st }}$ century and its implications in the North-West Province.

\section{Literature Review}

In the $21^{\text {st }}$ Century it will no longer be possible for curriculum experts, government officials, teacher unions or any other person or body to plan or control the curriculum from the outside. Instead, the curriculum will emerge as a result of dialogues between teachers and learners, politicians and pressure groups in the society. The quality of the dialogue will determine the quality of the outcome which, in a postmodern view, is the transformation of school curriculum. The NCS stresses high knowledge and high skills for all. This has been a feature of version 1 as well, but it has been argued that 
more emphasis on progression and less on integration will lead to more possibilities of achieving high knowledge and skills for all South Africa's learners, especially the historically disempowered (Mahomed,2004:6). According to Bertels (2002:478), change can be described as the process of analyzing the past to elicit present actions required for the future. It involves moving from a present state, through a transitional state to a future desired state. The focus of change is to introduce an innovation that brings something better, hence the strategies of designing, managing, implementing and evaluating the curriculum.

\subsection{Causes of resistance to change}

Kobola (2007:204-208) in Badugela (2012), indicates that at the individual level, some individuals exhibit resistance to change if they perceive a lack of personal involvement and control over unfolding events; other individuals have attitudes towards change based upon their previous experiences of organizational change. At a group level, resistance is caused by group cohesiveness, social norms, participation in decision-making and autonomy for self-determination of actions.

\subsection{Identifiable pressure groups and their influence}

Lofthouse (1994:1430) identified 7 pressure groups who held different ideologies with regard to curriculum content:

- Neo-classical or humanists put more emphasis on the conversation of an authoritative cultural tradition and stressed the need for curriculum to embody worthwhile knowledge.

- Vocational theorists defined the curriculum in terms of the transmission of useful knowledge that would capacitate an individual to become employable to serve the needs of society.

- Liberal-meritocratic theorists believed in competitive equality of opportunity. Thus, there was need to define the curriculum that would accentuates the need for learners to acquire personal autonomy within a framework of egalitarian freedoms against the background of a minimal state.

- Liberal-progressive group embraces an interventionist as opposed to a minimalist state. Stressing individual development, self-expression and cultural pluralism, this group depends on the state to encourage tolerance and understanding rather than competition and elitism.

- Socially critical theorists were in favor of the curriculum that can empower individuals to adopt a critical stance towards society. This group defines curriculum in terms of encouraging social change through transformative educational action.

- Religious theorists place secular knowledge in the context of transcendental values and wish the curriculum to explicitly convey spiritual values and beliefs.

- Pragmatic theory argues that a pragmatic stance to planning enables a proper focus to be placed upon coherent and mutually productive problem solving and learning capacities of

- Individuals and social groups.

\subsection{Causes of conflicts in curriculum control}

Due theorists` differing views, intergroup conflict as well as intragroup conflicts develop (Steys and Van Niekerk, 2002:77; Loock et al., 2003:22). Consequently, horizontal, vertical and role conflicts become visible among the various pressure groups. According to Loock, Grobler and Mestry (2009:43), conflict arises when two or more people have incompatible goals and one or both believe that the behavior of other prevents their achieving their own goals. They further assert that conflict involves peoples' feeling as well as their objectives, and both the feelings and their outcomes must be resolved. Conflict emerges when two or more people disagree about something. Conflict is deliberate, opposing behavior between different parties. Steyn and Van Niekerk (2002:84) explained that in mediation a third party uses various techniques to try to bring about agreement between the disputing parties in the conflict. Van der Westhuizen (2004:321) also emphasizes that in his role as a mediator in the conflict situation he should strive to get groups or individuals to the point where they admit the validity or basis of one another's view point so that they can discuss the problems frankly and objectivity.

\subsection{Conflict among the various curriculum managers at micro-level}

Phosa (2010:88) outlined the following causes of conflict:

Time: Because time is money, supervisors and staff are encouraged to act quickly. Teachers are forced to attend 
workshops for a very short period and go back to schools to implement. This lead to conflict between the department of education and school-based managers.

Experience: Some people have gained a vast amount of information and experience over time and believe that their perception is the only one.

Faith: Other people blindly or without question automatically accept all information as the truth without evaluating its strengths and weaknesses

Ego: Individual with ego problems have an attitude of "I must always show strength by being right the first time".

Poor training: Many people have not learned how to elicit, observe and identify human behavior, even though they are trying to influence the behaviors of the supervisor, staff, peers and offenders.

Oversensitivity: Some people believe that if someone wants you to know what happened, or what happen, he/she will tell you. At times oversensitive people try to avoid confrontation by not asking for sharing key information for fear that it may upset someone.

\subsection{Approaches to conflict resolutions among the various pressure groups}

Loocke, Grobler \& Mestry (2009:47) highlighted the following styles of handling conflict:

- Competing behavior is an aggressive, combative strategy in which one party tries to reach its goals and prevent the others from doing so. This behavior should be encouraged because competition leads to unhealthy rivalry.

- Collaborative behavior occurs when both parties try to satisfy all parties' interests, producing a 'win-win' situation in which both parties get most of what they want.This behavior must be adopted because it encourages team work.

- Compromising behavior: Here both parties have to give up something they value, leading to a 'lose-lose' situation which is acceptable for as long as they are not compromising the standard of education and the prosperity of the nation is not at stake.

- Avoiding style is an uncooperative, assertive style in which one attempts to withdraw from conflict. It does not help to avoid conflict because unresolved conflict may result in problems later because the problem will still be there and it becomes an ongoing thing without solution.

- Accommodating behavior: Here a party tries to satisfy the interest of the other party at their own expense, producing a 'win-lose' solution, in which one party gets what they want and the other gets nothing except the resolution of the conflict.

In this context it is suggested that conflict resolution should adopt the so-called dynamic and multi-faceted model which will accommodate (at the negotiation table) the needs all parties involved in curriculum control.

\subsection{Levels of curriculum control}

- National level: In South Africa, education is governed by two national departments, namely department of Basic education which is responsible for primary and secondary schools. We also have the Department of Higher Education and Training which is responsible for tertiary education and vocational training. All the provinces in South Africa have their own education departments which are responsible for implementing the policies of the national department.

- Local level: Provincial government feels that if they have total control of curriculum, it means that all students will receive the same level of education.

- Institutional levels: School principals are forced to manage the teachers who are not happy about the curriculum because they are not part of curriculum development, they were only given instructions from the Subject advisors on what to implement in schools. For an example, the implementation of C2005, with OBE as a method of delivery in schools.

- Individual levels: Teachers believes that they should control curriculum, but the problem may be that, they may end up teaching different content. Teachers do not want the curriculum to be controlled by the private sectors because the private sectors would only be beneficiaries in education. Aspects such as leadership and the centralization or decentralization of an educational system, that allows input and participation, may determine or influence the nature and degree of participation (Carl, 2005:223).

Prior to 1994, Duke (1990:183) revealed a variety of influences on the curriculum: 
- There are researchers and scholars who help generate new theories and knowledge and the professional associations that periodically demand curriculum revisions.

- There are blue ribbon commissions and politicians who call for curriculum reforms to address pressing national, regional and local concerns.

- There are the state and school district authorities who are charged with legal authorities to determine what should be taught.

- There are also test developers, college administrative officers and employers who influence the curriculum.

\subsection{Factors that influence curriculum design}

Curriculum means the subject that the student need to study to obtain a certain qualification. Curriculum planners, teachers, politicians and others involved in curriculum issues constantly deliberate about the nature of the desirable knowledge they believe learners should acquire (Jacobs et al., 2012:32). The Southern African Development Community (2000:22) identified the following factors which are determinants of a negotiated curriculum:

\subsubsection{Political factor}

a) Politics determine and define the goals, content, learning experience and evaluation strategies in education.

b) Curriculum materials and their interpretations are usually heavily influenced by political consideration.

c) Political considerations may play a part in the hiring of personnel that would ensure that political agenda are implemented.

d) Funding of education is greatly influenced by politics.

e) Entry into educational institutions and the examination systems are heavily influenced by politics.

\subsubsection{Social factors}

Curriculum designers should ensure that the curricular material accommodate the culture of the society that the curriculum is seeking to serve. To avoid conflicts, different religions and moral values should be considered when designing a curriculum.

\subsubsection{Economic factors}

The skills needed by industry should be translated into the content and learning experiences of the learners in the classroom. The market forces dictate what should be included in the national curriculum. Thus, teachers as agents of change are urged to consider economic demands when designing and implementing the national curriculum.

\subsubsection{Technology}

Modern curriculum designers cannot afford to ignore technology and its influence on the curricular. The intention is to equip the learners with the requisite electronic and computer skills and knowledge because modern technology is being used in teaching and learning.

\subsubsection{Environmental factor}

People have become insensitive to their surroundings and natural resources. Consideration for the environment must of necessity influence curriculum design to ensure the survival of future generation. It also influences material production.

\subsubsection{Child psychology}

Theories of learning and child development have to be considered when designing the content of the curriculum and how it is delivered. Child Psychology also influences scheduling and timetabling of curriculum. According to Steyn, Klerk and du Plessis (2009:30), every democratic society has the rights to hope and to expect that its children will grow up to be responsible citizens that will honour the rights of their fellow human rights, furthermore, all educational activities shall uphold and ensure the best interest of the child. 


\subsection{Theoretical framework}

Outcomes-based education (OBE) is a curriculum theory that grew out of two earlier teaching models, namely mastery learning and competency-based teaching. The idea of an outcomes-based curriculum was first broached by Johnson (1977) an American curriculum specialist who believed that the perennial curriculum model placed too much emphases on the aims and objectives of teachers and not enough on the end performance of students (Jacobs et al., 2004:57). They further argued that important skills which students do need for employment such as business and technical skills were not adequately taught to students. Attempts to change education have been philosophical as well as structured.

According to Lebepe (2010:7), the Institutional Change Management Model explains the relationships between the challenges of curriculum reform and delivery faced by schools that need to implement organisational change. These challenges include changes in the legislative framework, management approaches, whole school development planning, leadership approaches and curriculum development. Asmal (2000:5) submitted the report based on the view that curriculum should be clearly steered by principles that promote personal and social development and transformation for the $21^{\text {st }}$ Century. The social justice, equity and development are pursued by confronting a dual challenge:

- The challenge of the past and moving beyond the legacy of apartheid.

- The challenge of the future and developing a curriculum that will provide a platform for knowledge, skills and values for innovation and growth, and cultural creativity and tolerance for an African Renaissance.

According to Msila (2007), the introduction of OBE in South Africa was not only an attempt to change the education system, but also for the purpose of transforming society. This is based on the premise that when countries opt for educational change; they take cognizance of several other factors such as social, political and cultural issues. A revised set of National Curriculum Statements was published at the end of July 2001 for public discussion. The revisions were to simplify the structure, redefine the outcomes and provide more guidance on progression and promotion content. As part of the Revised National Curriculum Statements(RNCS), the assessment standards were prepared for each grade level, and in each outcome. The process and structures to support implementation were also developed. At the core of the RNCS are:

Eight learning area statements in the GET and FET band (DoE, 2001b:13) that affirm that each pupil will:

- Be equipped with the linguistic skills and the aesthetic and cultural awareness to function effectively and sensitively in a multilingual and multicultural society.

- Display a spirit of curiosity to enable creative and scientific discovery and display an awareness of health promotion.

- Adapt to an ever changing environment, recognizing that human understanding is consistently challenged and hence changes and grows.

- Use effectively a variety of ways to gather, analyze, organize, and evaluate numerical information and then communicate it effectively to a variety of audiences and models.

- Make informed decisions and accept accountability as a responsible citizen in an increasingly complex and technological society.

- Display the skills necessary to work effectively with others and organize and manage oneself, one's activities, and one's leisure time responsibly and effectively.

- Understand and show respect for the basic principles of human rights, recognizing the interdependence of members of society and

- Communicate effectively using visual, mathematical and language skills.

Report of the Task Team (1996:15) revealed these three approaches to education management currently at work in South Africa:

a) Approach 1: It focuses on technical administrative functions such as planning, organising, guiding and controlling. This approach dominated the public service during the apartheid years and infuses current thinking on education management. It is largely concerned with defining job descriptions, powers, functions and management relationship.

b) Approach 2: It attempts to reduce the emphasis on administrative process. It emphasizes the management and leadership functions of managers in the education system as a whole, including those at school level. It depends on management practices which emphasize the devolution of power, mission building, human resource development and school effectiveness.

c) Approach 3: The third approach is concerned with governance and with the relationship between policy, decision-making processes and implementation. The approach features strongly in the new education policy 
framework. It implies an emphasis on relationship building, stakeholder participation, the management of diversity and development.

\subsection{Components of the South African curriculum}

According to Jacobs et al. (2012:50), the South African curriculum is underpinned by behaviourist theory and specifically by the perennial curriculum model of Tyler (1949). In designing a curriculum, decisions have to be made about each of the five components in the design, namely, objectives, context, content, method and assessment.

- Objectives - These constituted the first component of curriculum design. CAPS place the focus on specific aims that guide learners towards developing the necessary knowledge and understanding of specific content. Aims and objectives are descriptions of knowledge, skills, attitudes and values leaners should have at the end of a particular grade.

- Context - Teachers have to create a teaching -learning context that invites learners to view new content critically against the background of their existing knowledge and experiences.

- Content - According to Jacobs et al. (2012:52), much of the content in the various South African curricular is aimed at preparing learners for the world of work. Content is the subject matter, which the government or some other educational authority prescribes, that should be taught in a specific course. The content taught prepares learners to live in a civilized community.

- Method - A teaching method is a specific approach that teachers can use to transfer knowledge to learners. Teachers are allowed to use any teaching method that is effective for teaching and learning.

- Curriculum theories Assessment - Assessment of learners consists of tasks that are used to obtain information about a learners' competence. Learners are assessed regularly according to assessment programme based on national assessment guidelines.

Those Critical Outcomes required learners to be able to: As compared to the seven (7) curriculum theories that were identified by Lofthouse (1994:143), in current year's curriculum theories that gained prominence during the $20^{\text {th }}$ century can be divided into two broad categories that is the traditional paradigm and the inquiry paradigm. Curriculum paradigm is a representative set of curriculum theories which are characterized by one particular approach to curriculum problems. According to Jacobs et al. (2010:39), among the large number of traditional curriculum theories, those that are currently deeply embedded in the curriculum thinking are:

a) The Liberal Theory: The main purpose of the curriculum should be to develop students' minds in such a way that they gain substantial insights into the great ideals of life such as truth, beauty, goodness, liberty, equality and justice. The teacher is regarded as the chief policy maker. In terms of this theory, curriculum is seen as being synonymous with content.

b) Dewey`s Experiential Theory: According to this theory, learners can only acquire knowledge through personal experiences. Thus, the purpose of a justifiable curriculum should be to facilitate personal growth by exposing each student as a person to as many relevant real-life experiences as possible. Justice must be done by focusing on each learner 's' interest, and not necessarily on material prescribed by the state.

c) The Behaviourist Theory(The Tylerian Theory): The behaviorists stress that each lesson in the curriculum should be divided into definite components and sections as determined by bureaucracies appointed to implement state policy and each lesson should result in a desirable change in the behavior of a learner. According to Jacobs et al. (2012:38), this theory was initiated by Tyler in 1949 who builds his theory around four fundamental questions each of each led in due time to the development of perennial curriculum.

d) The Pragmatic Theory: This curriculum theory approaches learning through experience. The child's interest, needs and experience are taken into account. It advocates for knowledge construction by the learner.Thus, the NCS builts its learning outcomes for Grade 10-12 on the Critical and Development Outcomes that were inspired by the constitution and developed through a democratic process (DoE, 2003:3).

- Identify and solve problems and make decisions using critical and creative thinking;

- Work effectively with others as members of a team, group, organization and community;

- Collect, analyze, organize and critically evaluate information;

- Communicate effectively using visual, symbolic and or language skills in various modes;

- Use science and technology effectively and critically showing responsibility towards the environment and the health of others; and 
- Demonstrate an understanding of the world as a set of related systems by recognizing that problem solving context do not exist in isolation.

The Developmental Outcomes required learners to be able to:

- Reflect on and explore a variety of strategies to learn more effectively;

- Participate as responsible citizens in the life of local, national and global communities;

- Be culturally and aesthetically sensitive across a range of social context;

- Explore education and career opportunities, and

- Develop entrepreneurial opportunities.

Three imperatives for curriculum managers in schools (Lofthouse, 1995:30):

- Curriculum planning, development, delivery and assessment can no longer remain the preserve of individual classroom practitioners. Effective curriculum coverage demands collaborative planning and integrated approaches to curriculum delivery.

- The development of complex curricular and the consequent fragmentation of traditional subject divisions create pressures for institutions-wide policies on issues as diverse as assessment, record-keeping, numeracy, learner support, the sharing of diagnostic information and independent learning. Individual curriculum managers are thereby under pressure to help define and then conform to whole school policy.

- External accountability pressures and the need to ensure complete curriculum coverage reinforce the need to observe classroom practice and offer constructive feedback on the strengs.

The above aims provide a context within which schools develop their own curriculum in collaboration with all relevant stakeholders (Department of Education and Skills, 2004).

\subsection{Aims of the school curriculum}

These main aims are singled out:

- The school curriculum should aim to provide opportunities for all pupils to learn and to achieve. Curriculum should equip learners with the essential learning skills of literacy, numeracy and information and communication technology.

- The school curriculum should aim to promote pupils spiritual, morals, social and cultural development and prepare all pupils for the opportunities, responsibilities and experience of life in order to capacitate them to contribute to the development of a just society. It should also prepare pupils for the next step in their education, training and employment and equip them to make informed choices at school and throughout their lives.

The main purposes of the National Curriculum are:

- To establish an entitlement: the idea is to develop knowledge, understanding skills and attitude for selfdevelopment.

- To establish standards: the Department set targets for improvement, measure progress towards those targets, monitor and compare performances.

- To promote continuity and coherence: It facilitates the transition of pupils between school and Phase of Education and provides a foundation for lifelong learning.

- To promote public understanding: It provides a common basis for discussion of education issues among lay and professional groups, including pupils, parents, teachers, governors and employers.

\section{Research Design and Methodology}

The research paper employed the qualitative research design which served as a process consisting of a series of systematic steps purposively chosen and followed when carrying out the research study (Cresswell, 2009). Van der Walt \& Kruger (2010:18), asserts that research design describes how the study will be conducted, it also summarizes the procedures for conducting the study, including when, from whom and under which conditions the data is to be obtained. The advantage of quantitative approach is that it measures the reaction of a great many people to a limited set of questions, thus facilitating comparison and statistical aggregation of data. 


\subsection{Tools for data collection and data analysis}

Using the case study method, in-depth face to face interviews were conducted with the purposively chosen participants. These interviews were interlinked with observation and reflective notes. Document analysis was also used for collecting qualitative data. Qualitative data was analyzed using critical discourse analysis strategy which is recommended by Maree (2007:102).

\subsection{Delimitation of the study}

This was a qualitative study focused on identifying the legitimate role players over the curriculum control with emphasis on curriculum designing, implementation and curriculum management. The study was confined to the North West Provincial Department of Education in Ngaka Modiri Molema District. The field of the study was Curriculum Management.

\subsection{Ethical consideration}

The Constitution of South Africa, Act 108 of 1996, chapter 2, provides rights for every citizen unconditionally. The researcher as directed by the provision of the Act was compelled to observe the citizens 'rights' by strictly observing the principles stipulated by the Bill of Rights. The following principles were observed: all participants were briefed about the purpose of the report. The principle of anonymity was observed by not asking participants to reveal their personal identities, (Neuman, 2003:126). Permission had to be granted by the participants to participate in the study. Thus, the principles of respect and trust were followed. Researcher ensured that participants were not subjected to any psychological, physical or emotional harm.

\section{Results}

Literature review revealed that there is need for a radical break away from apartheid-driven curriculum to outcomesdriven curriculum which is in favor of educational practices for the success of the country, the community and the individuals. The different pressure groups involved in curriculum management and control claim to own the curriculum. Unfortunately, due to their different aims and/or their philosophical principles underpinning their curriculum theory and practices, there is a problem of role confusion. Despite the fact that there is a problem of role confusion, one thing that emerged is that all legitimate stakeholders should be granted the right to participate (Hystteen,2005:51), only if their aim is to transform the "apartheid curriculum" into a transformative system of education that is geared towards the stated state's goals of equity, redress, democracy and participative governance

Unfortunately, the contesting groups were not ready to compromise their position. Consequently, their unresolved conflicts most often gave rise to unhealthy" hot debates" which were commonly referred to as "war of words." The contest is still continuing because no pressure group wants to compromise its position. Other groups resist change because they do not have personal control over curriculum. The Review Committees' report indicates that fierce debate on C2005 is an ongoing feature in many staffrooms today, indicating a low level of institutionalization (Blignaut, 2001:4).It is apparent that as the environment changes and societies portray new needs due to the changing paradigms, the curriculum has to keep on changing to address these arising needs of the $21^{\text {st }}$ Century these changing paradigms come with new unending debates.

A particularly South African manifestation of community participation is that of stakeholders' participation, for example, SASA makes provision for the participation of stakeholders such as parents, teachers, students and the community School Governing Bodies( Hyssteen,2005:51). This implies that legitimate stakeholders should be granted the right to participate in school governance structures.

\section{Recommendations}

Based on the above stated findings it is obvious that in the $21^{\text {st }}$ Century, all negotiated talks should be governed by the principles of democracy. It is also obvious that the transition from a culture of separate development requires a model that is dynamic enough to reflect the principles of social reconstruction, social interaction and sharing of ideas, based on the principles of freedom, justice and all human rights, tolerance and solidarity that strives to prevent conflict by creating "winwin" situations. Therefore, it is recommended that in order to bring the continuous "cold war" over the curriculum control to an end, a collaborative model that would accommodate all legitimate stakeholders as equal partners to participate in 
curriculum design, implementation, management and evaluation be adopted. It is recommended that concerted efforts be made to encourage:

- positive competition which will in turn encourage robust discussion of different opinions by the various role players in curriculum control and management;

- positive collaboration which will produce a "win-win" situation;

- adopting a compromising position so that no party should feel that it is losing more than the other; and

- also put effort in accommodating those role players who might feel sidelined because of lack of resources.

In essence, the various pressure groups should strive to work together as a team, to exercise control with the voice of the people, with a view of meeting the needs of the people. In this suggested model, the solution is not confrontation. The right move is to make winners of the losers and losers of the winners. The winning strategy is to ensure that nobody sinks, but the different stakeholders should be educated to swim together with the current times. The way forward is for all legitimate stakeholders and the Department of Education of the day to work together to redress the challenges of the $21^{\text {st }}$ Century. Since the phenomenon under investigation is multi-dimensional and in a state of flux, the suggested model for curriculum control must of necessary reflect this multi-dimensionality.

\section{Conclusion}

Based on the proceeding information, it is obvious that the "hot debate" over curriculum control is caused not only by the fact that there were different curriculum pressure groups each one of which had a different ideological stance but each pressure group aspired to play a significant role. Therefore, the conflict is not caused by the fact that there are different opinion or different role players in curriculum planning and management, but by the fact that lack of role clarity has led to this opinions and role players playing into or being seen to be interfering with each other's role. It is important that the negotiated talks be guided by clarity of role specification, transparency, equity, redress, access and participation.

\section{References}

Badugela, T.M. (2012). Problems facing educators in implementing the National Curriculum Statement: The case of Tshifhena Secondary School, Vhembe District, Limpopo Province, South Africa. University of South Africa.

Blignaut, S. (2001). The implementation of Curriculum 2005 with reference to Micro Implementation. Paper delivered at the 2001 Conference of Education Association of South Africa (EASA), at the University of Port Elizabeth 16 - 18 January 2001.

Carl, A. (2005). The "voice of the teacher" in curriculum development: a voice crying in the wilderness. South African Journal of Education. Vol 25(4)223-228).

Chisholm, L. (2003). The Politics of Curriculum Review and Revision in South Africa. Paper presented at Oxford International Conference on Education and Development at the session on Culture, Context and the Quality of Education.

Cohen, L. Manion, L. \& Morrison, K. (2011). Research Methods in Education. United States of America. Ashford Colour Press.

Constitution of the Republic of South Africa. (1996). Pretoria: Government Printers.

Creswell, J.W. (2007). Qualitative Inquiry and Research Design: Choosing among Five Approaches (2nd edition). California: Sage Publication.

Czerniewicz, L., Murray, S. \& Probyn, M. (2000). A research paper on the role of learning support materials in Curriculum 2005. National Institute of Curriculum Research and Development. Government printers.

Jacobs, M., Vilakazi, N. \& Gawe, N. (2010). Teaching-Learning Dynamics: A participative approach for OBE. Sandton: Heinemann publishers. practice. London: Sage publication.

Lebepe, T.O. (2010). The impact of institutional Jacobs, M., Vilakazi, N. \& Gawe, N. (2012 Teaching-Learning Dynamics: A participative approach for OBE. Sandton: Heinemann publishers.

Kelly, A.V. (2009). The curriculum, theory and change on curriculum reform in schools of the North West Province. North- West University (Mafikeng campus).

Lofthouse, M., Bush, T.,Coleman, M.; O'Neill, J., West-Burnham, J. \& Clover,D. (1995). Managing the curriculum. University of Leicester. Pietman publishing.

Loock, C. Grobler, B. \& Mestry, R. (2009). Human Resource Management in Education: Rebalancing the Scale. Pretoria: Van Schaik Publisher.

Maree, K. (2007). First steps in research. Pretoria: Van Schaik Publishers.

Msila, V. (2007). From Apartheid Education to the Revised National Curriculum Statement: Pedagogy for Identity Formation and Nation Building in South Africa. Nordic Journal of African Studies 16(2):146-160).

Neuman, W.L. (2003). Social research methods: Qualitative and quantitative approaches. Boston: Pearson Education.

Phosa, L. (2011). Strategic Public Human Resource Management South Africa. UNISA.

Southern African Development Community. (2000). Curriculum theory, design and assessment. The commonwealth of learning.

Steyn. J.C., de Klerk, J. \& du Plessis, W.S. (2009). Education for Democracy. South Africa: Wachwa Publishers CC. 
Steyn, G.M. \& Van Niekerk, E.J. (2002). Human Resource Management in Education. Pretoria: Unisa.

Van Huyssteen, A. (2005). An Introduction to Constitutional Principles in Education: a South African perspective. Potchefstroom: Platinum Press.

Van der Walt, G. \& Kruger, J. (2010). Foundation of Education Research: Study guide for FOER 611.(Published) Potchefstroom: NorthWest University. 